\title{
BJC
}

\section{Comment on 'Anti-tumour activity of abiraterone and diethylstilboestrol when administered sequentially to men with castration-resistant prostate cancer'}

\author{
$J_{\text {Shamash }}^{*, 1}$ and S-J Sarker ${ }^{2}$ \\ ${ }^{1}$ St Bartholomew's Hospital, 7th Floor, Gloucester House, Little Britain, UK and ${ }^{2}$ Centre for Experimental Cancer Medicine, Queen \\ Mary University of London, London, UK
}

Omlin et al (2013) report the anti-tumour activity of diethylstilbestrol (DS) and abiraterone (AA) in castration-resistant prostate cancer and suggest substantial activity of AA in DS pretreated patients. Their retrospective review includes patients who were post docetaxel as well as those who were chemotherapy naive. We feel that the additional activity of AA may have been overstated. Abiraterone is always combined with a corticosteroid - and therefore the comparison is between AA and a corticosteroid vs DS and a corticosteroid. Most of the patients in the series described by Omlin et al (2013) received DS without a corticosteroid. In the paper by Ryan et al (2013) median time to progression (TTP) was doubled when AA and prednisone was compared with prednisone alone (11.1 vs 5.6 months). When the combination of dexamethasone and DS was compared to dexamethasone alone, a similar effect was seen (8.6 vs 4.5 months) in chemotherapy-naive patients (Shamash et al, 2011), see table below.

\begin{tabular}{|c|c|c|}
\hline & $\begin{array}{l}\text { Dexamethasone with deferred DS } v s \text { dex- } \\
\text { amethasone and DS (Shamash et al, } \\
\text { 2011) }\end{array}$ & $\begin{array}{l}\text { Prednisone vs AA and } \\
\text { prednisone (Ryan et al, } \\
\text { 2013) }\end{array}$ \\
\hline Randomisation & Yes & Yes \\
\hline Double blind & No & Yes \\
\hline ECOG PS & $0-3$ & $0-1$ \\
\hline PSA progression & PCWG1 & PCWG2 \\
\hline Patients & All chemo naïve & All chemo naive \\
\hline PFS (rad) & Not stated & 16.5 vs 8.3 \\
\hline Median TTP (PSA) & $\begin{array}{l}\text { All: } 8.5 \text {, dexamethasone alone: } 4.5, \mathrm{DdS}^{*} \\
\text { (overall): } 8.4 \text {, DS: } 8.6\end{array}$ & $\begin{array}{l}\text { Prednisone: } 5.6 \mathrm{AA} / \text { pre- } \\
\text { dnisone: } 11.1\end{array}$ \\
\hline \multirow[t]{2}{*}{ Median overall survival (OS) } & All: 19.1 (95\% CI: $16.8-21.4)$, DdS: 18.8 , & \multirow[t]{2}{*}{$27.2 v s>27.2$} \\
\hline & $\begin{array}{lr}\text { DS: } & 19.4 \\
\text { (33\% went on to receive chemotherapy) }\end{array}$ & \\
\hline Median OS $(\mathrm{PS}=0)$ & $\begin{array}{llll}\text { All: } & 28.7, & \text { DdS: } & 26.2, \\
\text { DS: } 38.1 & & & \end{array}$ & $>27.2$ \\
\hline HR for survival & $0.79(0.57-1.08):$ DS $v s$ DdS & $0.75(0.61-0.93)$ \\
\hline $\mathrm{HR}$ for survival $(\mathrm{PS}=0)$ & $0.63(0.33,1.2)$ & $0.71(0.55,0.92)$ \\
\hline PSA decline $\geqslant 50 \%$ & $\begin{array}{l}\text { All: } 66 \% \text {, dexamethasone alone: } 50 \% \text {, DS } \\
68 \%\end{array}$ & $\begin{array}{l}\text { Prednisone } 24 \% \text { vs AA/ } \\
\text { prednisone } 62 \%\end{array}$ \\
\hline
\end{tabular}

$\mathrm{DdS}^{*} \mathrm{DS}$ was added when the patient progressed.

We feel that some of the responses described could also be explained by the fact that DS was given before docetaxel and AA after. There is evidence that chemotherapy following failure of a hormone therapy allows that treatment to work again when patients are rechallenged with the same hormone therapy.

We have reviewed our data on patients who went on to receive DS and dexamethasone followed on progression by AA and prednisolone. We have identified 12 patients who had DS and dexamethasone immediately prior to AA and prednisolone. Eleven had prior treatment with docetaxel. Five out of 12 had a 50\% PSA response to DS. Progression-free survival was 7.0 months (range 3.6-8.7), for the whole group it was 3.4 months (range 1.1-8.7). For subsequent AA and prednisolone only one patient responded (PFS 8.1 months). The overall PFS was 1.8 months (range 0.6-8.1). For the 11 who received docetaxel, 10 had prior DS. Five out of 10 had a 50\% PSA response with a PFS of 7.0 months (range 1.0-15.0). For this group, overall PFS was 5.75 months (range 1-15). Four out of these five subsequently re-responded following docetaxel.

This supports our view that many patients who respond to hormone therapy prechemotherapy will subsequently respond to the same hormonal therapy afterwards (Shamash et al, 2008) and that cross-resistance between AA and DS when combined with steroids may be much greater than has been suggested.

\section{REFERENCES}

Omlin A, Pezaro CJ, Zaidi S, Lorente1 D, Mukherjil D, Bianchinil D, Ferraldeschil R, Sandhul S, Dearnaley D, Parker C, As NV, de Bono1 JS, Attard C (2013) Antitumour activity of abiraterone and diethylstilboestrol when administered sequentially to men with castration-resistant prostate cancer. Br J Cancer 109: 1079-1084. Ryan CJ, Smith MR, De Bono JS, Molina A, Logothetis CJ, de Souza Paul, Fizazi K, Mainwaring P, Piulats JM (2013) Abiraterone in metastatic prostate cancer without previous chemotherapy. N Engl J Med 368: 138-148.

Shamash J, Davies A, Ansell W, Mcfaul S, Wilson P, Oliver T, Powles T (2008) A phase II study investigating the re-induction of endocrine sensitivity following chemotherapy in androgen-independent prostate cancer. Br J Cancer 98(1): 22-24. 
Shamash J, Powles T, Sarker SJ, Protheroe A, Mithal N, Mills R, Beard R, Wilson P, Tranter N, O'Brien N, McFaul S, Oliver T (2011) A multi-centre randomised phase III trial of Dexamethasone vs Dexamethasone and diethylstilbestrol in castration-resistant prostate cancer: immediate vs deferred Diethylstilbestrol. Br J Cancer 104: 620-628. (c) (1) (2) (2) This work is licensed under the Creative Commons Attribution-NonCommercial-Share Alike 3.0 Unported License. To view a copy of this license, visit http://creativecommons. org/licenses/by-nc-sa/3.0/

\title{
Reply: 'Comment on Anti-tumour activity of abiraterone and diethylstilboestrol when administered sequentially to men with castration-resistant prostate cancer'
}

\author{
A Omlin ${ }^{1}$, C J Pezaro ${ }^{1}$, S Zaidi ${ }^{2}$, D Lorente ${ }^{1}$, D Mukherji ${ }^{1}$, D Bianchini ${ }^{1}$, R Ferraldeschi ${ }^{1}$, S Sandhu ${ }^{1}$, \\ D Dearnaley ${ }^{2}, \mathrm{C} \mathrm{Parker}^{3}, \mathrm{~N}$ Van $\mathrm{As}^{4}$, J S de Bono ${ }^{1}$ and G Attard ${ }^{\star, 1}$ \\ ${ }^{1}$ Prostate Cancer Targeted Therapy Group and Drug Development Unit, Section of Medicine, The Royal Marsden NHS \\ Foundation Trust and The Institute of Cancer Research, Downs Road, Sutton, Surrey SM2 5PT, UK; ${ }^{2}$ Academic Urology Unit, \\ Sutton, The Royal Marsden NHS Foundation Trust and The Institute of Cancer Research, Downs Road, Sutton, Surrey, UK; \\ ${ }^{3}$ Academic Urology Unit, The Royal Marsden NHS Foundation Trust, Downs Road, Sutton, Surrey, UK and ${ }^{4}$ Academic Urology Unit, \\ The Royal Marsden NHS Foundation Trust, Fulham Road, Chelsea, London, UK
}

Sir,

We thank Shamash and Sarker for their interest in our recent article (Omlin et al, 2013). They make three comments: first, that the activity of diethylstilboestrol (DES) when combined with a corticosteroid such as dexamethasone (D) is increased compared to DES alone; second, that chemotherapy may re-induce sensitivity to a hormonal agent; finally, their experience in 11 patients who received the sequence of docetaxel followed by DES and D and then abiraterone acetate (AA) and prednisone. In this setting the activity of AA was limited, as indicated by a median progressionfree survival (PFS) of 1.8 months (range 0.6-8.1).

We wish to clarify that we did not report any data on DES activity prior to treatment with AA because it was not possible to get complete DES activity data for patients treated outside of our institution. We therefore only reported duration of DES treatment. Our large institutional experience with single-agent DES and aspirin in 231 men with castration resistant prostate cancer (CRPC) showed a median time to PSA progression of 4.6 months, $\geqslant 50 \%$ PSA declines in $28.9 \%$ of patients and a VTE rate of $9.9 \%$ (Wilkins et al, 2012). We acknowledge that the activity of DES may be modestly higher when it is combined with $D$, which has been shown to have single-agent anti-tumour activity in men with castration-resistant prostate cancer, although there is little evidence that this therapeutic manoeuvre imparts significant clinical benefit (Venkitaraman et al, 2008). The comparison of DES plus D with D alone by Shamash et al (2011) is interesting but raised concerns that DES is associated with a major risk of serious toxicity, unlike AA, with veno-thromboembolic events (VTEs) in $22 \%$ of patients despite prophylactic treatment with aspirin. Given that AA provides overall survival benefit in Phase III trials, AA is a preferable treatment to DES for CRPC (de Bono et al, 2011; Ryan et al, 2013). Indeed we believe that there may now be little merit in administering DES to patients suffering from CRPC.

The hypothesis that chemotherapy may induce sensitivity to endocrine agents is also intriguing. However, clinical trials of AA and enzalutamide have all reported higher response rates prechemotherapy than afterwards, suggesting overlapping mechanisms of resistance (Scher et al, 2010, 2012; de Bono et al, 2011; Ryan et al, 2013). The study referenced by Shamash et al (2008) did not utilise taxanes (that through their postulated disruption of AR signalling may be associated with cross-resistance with endocrine treatments) and allowed cessation of androgen deprivation with $49 \%$ of patients having non-castrate levels of testosterone at the 